\title{
Prostatic Duct
}

National Cancer Institute

\section{Source}

National Cancer Institute. Prostatic Duct. NCI Thesaurus. Code C13102.

A small canal that receives prostatic secretions from the glandular tubules and discharges it through the prostatic portion of the urethra. 